\title{
Comparison of almitrine bismesylate and medroxyprogesterone acetate on oxygenation during wakefulness and sleep in patients with chronic obstructive lung disease
}

\author{
E Daskalopoulou, D Patakas, V Tsara, F Zoglopitis, E Maniki
}

\begin{abstract}
The effects of almitrine bismesylate and medroxyprogesterone acetate on oxygenation during wakefulness and sleep were compared in six patients with chronic obstructive lung disease and carbon dioxide retention. Patients received $1.5 \mathrm{mg} / \mathrm{kg}$ almitrine (a peripheral chemoreceptor stimulant), $100 \mathrm{mg}$ of medroxyprogesterone (a central respiratory stimulant), or matched placebo daily for 15 days in random order in a crossover trial. When subjects were awake almitrine increased the ventilatory response to hypoxia and increased arterial oxygen tension $\left(\mathrm{PaO}_{2}\right)$ to a greater extent than medroxyprogesterone, whereas medroxyprogesterone augmented the ventilatory response to hypercapnia and decreased arterial carbon dioxide tension $\left(\mathrm{PaCO}_{2}\right)$ to a greater extent than almitrine. Neither drug influenced sleep architecture significantly, except that medroxyprogesterone increased the number of arousals. Almitrine had a more favourable effect than placebo on oxygenation as estimated from arterial oxygen saturation $\left(\mathrm{SaO}_{2}\right)$ during the different stages of sleep, the number of episodes of hypoxaemia, and the amount of time that $\mathrm{SaO}_{2}$ was below $80 \%$. The only change with medroxyprogesterone by comparison with placebo was a decrease in the number of hypoxaemic episodes. It is concluded that both active drugs improved blood gases during wakefulness, but that $1.5 \mathrm{mg} / \mathrm{kg}$ of almitrine is superior to 100 mg of medroxyprogesterone in improving $\mathrm{SaO}_{2}$ during sleep.
\end{abstract}

Unit, Department of Internal Medicine,

University of

Thessaloniki

D Patakas

F Zoglopitis

E Manik

Second Pulmonary

Clinic, George

Papanikolaou General

Hospital, Thessaloniki,

Greece

E Daskalopoulou

V Tsara

Address for reprint requests: Dr E DaskalopoulouVlachogianni, Ikismos Lida-Maria, Alkistis II GR-570 01 Thermi,

Thessaloniki, Greece.

Accepted 11 June 1990

During the last few years there has been renewed interest in the use of respiratory stimulants to alleviate hypoxaemia in patients with chronic obstructive pulmonary disease during wakefulness and sleep. Some of the factors responsible for this renewed interest are the recognition that normoxaemic patients with chronic obstructive pulmonary disease may have hypoxaemic episodes during sleep ${ }^{1}$; the development of respiratory stimulants for long term oral use with few side effects; the reluctance of some patients to have long term oxygen therapy; and the various practical
The most commonly used respiratory stimulants are medroxyprogesterone acetate and almitrine bismesylate. Although the two drugs act by different mechanisms, both have been shown to improve blood gases during wakefulness and sleep..$^{2-4}$ Medroxyprogesterone, which is considered to be a central chemoreceptor stimulant, increases alveolar ventilation during wakefulness and sleep. ${ }^{3}$ Almitrine, a peripheral chemoreceptor stimulant, increases alveolar ventilation and improves the ventilation-perfusion ( $\mathbf{V} / \mathbf{Q})$ ratio. ${ }^{5}$

The aim of this study was to compare the effects of medroxyprogesterone and almitrine on oxygenation during wakefulness and sleep in patients with chronic obstructive lung disease and carbon dioxide retention. This is, we believe, the first direct comparison of these agents in the same individuals.

\section{Methods}

PATIENTS

We studied six non-obese men (mean age 62 (SD 6) years) with chronic obstructive lung disease. Their respiratory function and blood gas values are shown in table 1. All were clinically stable for more than four weeks before and throughout the study. None was receiving long term domiciliary oxygen therapy. They continued their usual medications (inhaled beta ${ }_{2}$ sympathomimetics, theophylline derivatives, diuretics, digoxin) in unchanged dosage throughout the study.

\section{STUDY DESIGN}

The study was designed as a placebo controlled, crossover trial. After a selection night to exclude patients with the sleep apnoea syndrome and for purposes of familiarisation, subjects received in random order $1.5 \mathrm{mg} / \mathrm{kg}$ problems associated with oxygen therapy.
Table 1 Mean (SD) values for respiratory function measures and arterial blood gases

\begin{tabular}{|c|c|}
\hline Pulmonary function $\left({ }^{\circ}\right.$ ored $)$ & Arterial blood gases \\
\hline $\begin{array}{l}\mathrm{FEV}_{1} 35(11) \\
\operatorname{VC} 51(4) \\
\operatorname{RV} 180(18) \\
\text { MMER 13(5) }\end{array}$ & $\begin{array}{l}\mathrm{PaO}_{2} 51(3) \mathrm{mm} \mathrm{Hg} \\
\mathrm{PaCO}_{2} 50(4) \mathrm{mm} \mathrm{Hg} \\
\mathrm{pH} 7.41(0.02) \\
\mathrm{SaO}_{2} 83(3) \%\end{array}$ \\
\hline
\end{tabular}

Conversion to SI units: $1 \mathrm{~mm} \mathrm{Hg} \approx 0.133 \mathrm{kPa}$ capacity; RV-residual volume; MMER-maximum mid expiratory flow $(25-75 \% \quad \mathrm{VC}) ; \mathrm{PaO}_{2}$-arterial oxygen tension; $\mathrm{PaCO}_{2}$ - arterial carbon dioxide tension; $\mathrm{SaO}_{2}-$ arterial oxygen saturation. $1 \mathrm{~mm} \mathrm{Hg} \approx 0.133 \mathrm{kPa}$.
$\mathrm{FEV}_{1}$ - forced expiratory volume in one second; $\mathrm{VC}$-vital 
almitrine a day divided into two doses, $100 \mathrm{mg}$ of medroxyprogesterone a day divided into two doses, or matched placebo for 15 days. Drugs and placebo were administered at 0800 and 2000 hours. An acclimatisation night in the sleep laboratory preceded every sleep study. Each period of study was separated by a four week washout period.

The protocol was approved by the ethical committee of the department of internal medicine and each patient gave written, informed consent.

\section{AWAKE STUDY}

The study procedures were carried out in the morning, one hour after administration of the drugs.

Arterial blood samples were taken at rest with the patient in the supine posture through a small cannula inserted in the radial artery. Blood was analysed for arterial oxygen tension $\left(\mathrm{PaO}_{2}\right)$ and arterial carbon dioxide tension $\left(\mathrm{PaCO}_{2}\right)$ by electrodes (Radiometer, Copenhagen). The alveolar-arterial oxygen difference $\left(\mathrm{A}-\mathrm{aDo}_{2}\right)$ was computed according to the simplified formula

$$
\mathrm{PaO}_{2}=\mathrm{PIO}_{2}-1 \cdot 25 \cdot \mathrm{PaCO}_{2} .
$$

Spirometry was performed with a water sealed Godart spirometer. Lung volumes were measured by the helium dilution method. ${ }^{6}$

The ventilatory response to hypercapnia was estimated by the rebreathing method of Read. ${ }^{7}$ The ventilatory response to hypoxia was assessed by the use of progressive hypoxia with progressive hypercapnia.

\section{SLEEP STUDY}

All patients underwent a whole night polysomnographic study with simultaneous recording of the electroencephalogram, elec-

Table 2 Mean (SD) values for blood gas tensions, alveolar-arterial oxygen difference ( $A$ $\left.a \mathrm{Do}_{2}\right)$, and ventilatory response to hypoxia and hypercapnia after administration of placebo, medroxyprogesterone, and almitrine in the six patients

\begin{tabular}{lllll}
\hline & Placebo & Medroxyprogesterone & Almitrine & $p^{\star}$ \\
\hline & $53(2)$ & $56(3)$ & $58(2)$ & $<0.05$ \\
$\mathrm{PaO}_{2}(\mathrm{~mm} \mathrm{Hg})$ & $52(4)$ & $44(2)$ & $47(2)$ & $<0.01$ \\
$\mathrm{Paco}_{2}(\mathrm{~mm} \mathrm{Hg})$ & $31(3)$ & $38(4)$ & $33(4)$ & $<0.05$ \\
$\begin{array}{l}\mathrm{A}-\mathrm{aDO}_{2} \text { (mm Hg) } \\
\begin{array}{l}\mathrm{Hypercapnic} \\
\text { ventilatory response } \\
(1 / \text { min/mm Hg) }\end{array}\end{array}$ & $0.93(0.5)$ & $1.19(0.6)$ & $0.94(0.5)$ & $<0.05$ \\
$\begin{array}{l}\text { Hypoxic } \\
\text { ventilatory response } \\
\Delta \dot{\mathrm{VE}}_{79}(1 / \mathrm{min})\end{array}$ & $6.67(5.1)$ & $7.43(4.2)$ & $9.68(4.2)$ & $<0.05$ \\
\hline
\end{tabular}

*Comparison between medroxyprogesterone and almitrine; the paired $t$ test was used with the absolute values.

Conversion to SI units: $1 \mathrm{~mm} \mathrm{Hg} \approx 0.133 \mathrm{kPa}$.

$\Delta \mathrm{VE}_{79}$-change in minute ventilation when $\mathrm{SaO}_{2}$ is $79 \%$.

Other abbreviations as in table 1.

Table 3 Data on sleep quality (mean ( $S D$ ) values)

\begin{tabular}{lcccl}
\hline & Placebo & Medroxyprogesterone & Almitrine & $p^{\star}$ \\
\hline Time in bed (min) & $308(49)$ & $324(35)$ & $316(29)$ & NS \\
Sleep latency (min) & $24(11)$ & $17(13)$ & $21(14)$ & NS \\
Sleep period time (min) & $285(24)$ & $307(31)$ & $295(18)$ & NS \\
Total sleep time (min) & $218(15)$ & $251(38)$ & $229(22)$ & NS \\
Sleep efficiency index $(\%)$ & $71(6)$ & $77(12)$ & $76(9)$ & NS \\
Arousals/hour & $17(4)$ & $25(3)$ & $18(4)$ & $<0 \cdot 001^{\star}$ \\
\hline
\end{tabular}

^Comparison between placebo and medroxyprogesterone; the paired $t$ test was used. tro-oculogram, and submental electromyogram. ${ }^{9}$ Air flow was detected by continuously analysing for carbon dioxide (Godart, mark III) at the nose and mouth through a common catheter. Rib cage and abdominal motion was monitored by respiratory inductance plethysmography with two bands (Respitrace Jacket, Ambulatory Monitoring, White Plains, New York). Oxygen saturation was monitored by a Hewlett Packard (47201A) ear oximeter. All variables were recorded on an eight channel recorder (Alval) running at $15 \mathrm{~mm} / \mathrm{s}$.

Baseline $\mathrm{SaO}_{2}$ when the patient was awake was defined as the mean $\mathrm{SaO}_{2}$ over a period of 10 minutes before sleep; a hypoxaemic episode was defined as a fall in $\mathrm{SaO}_{2}$ of $10 \%$ or more below baseline $\mathrm{SaO}_{2}$ lasting for at least one minute.

\section{STATISTICAL ANALYSIS}

The data were analysed by comparing the values obtained after administration of placebo, medroxyprogesterone, and almitrine with the paired $t$ test. Values of $\mathrm{p}$ of 0.05 or less were considered significant.

\section{Results}

\section{AWAKE STUDY}

Both medroxyprogesterone and almitrine had a favourable effect on arterial blood gas tensions during wakefulness without any change in maximum expiratory flow or lung volumes.

Almitrine had the greater effect on $\mathrm{PaO}_{2}$ and this was significantly different from that seen with medroxyprogesterone (table 2). On the other hand, medroxyprogesterone caused the greater reduction in $\mathrm{PaCO}_{2}$ and this was significantly greater than the reduction seen after almitrine.

There was an increase in the calculated alveolar-arterial oxygen difference $\left(\mathrm{A}-\mathrm{aDo}_{2}\right)$ after medroxyprogesterone (table 2).

The ventilatory response to hypercapnia was increased after medroxyprogesterone and almost unchanged after almitrine administration (table 2). The ventilatory response to hypoxia increased greatly after almitrine and to a lesser degree after medroxyprogesterone administration.

\section{SLEEP STUDY}

There were no differences in the percentage of each sleep stage seen on the different study nights except that the number of arousals was increased after medroxyprogesterone ( $p<$ 0.001 , table 3). Sleep architecture was unchanged, as judged by the duration of sleep stages expressed as a percentage of sleep period time (figure).

Mean $\mathrm{SaO}_{2}$ was increased during REM and non-REM sleep after medroxyprogesterone and to a greater extent after almitrine. $\mathrm{SaO}_{2}$ was significantly higher after almitrine than after placebo (table 4). The lowest $\mathrm{SaO}_{2}$ recorded during sleep, the time for which $\mathrm{SaO}_{2}$ fell below $80 \%$, and the number of hypoxaemic episodes were less after administration of the active drugs, almitrine causing a greater 


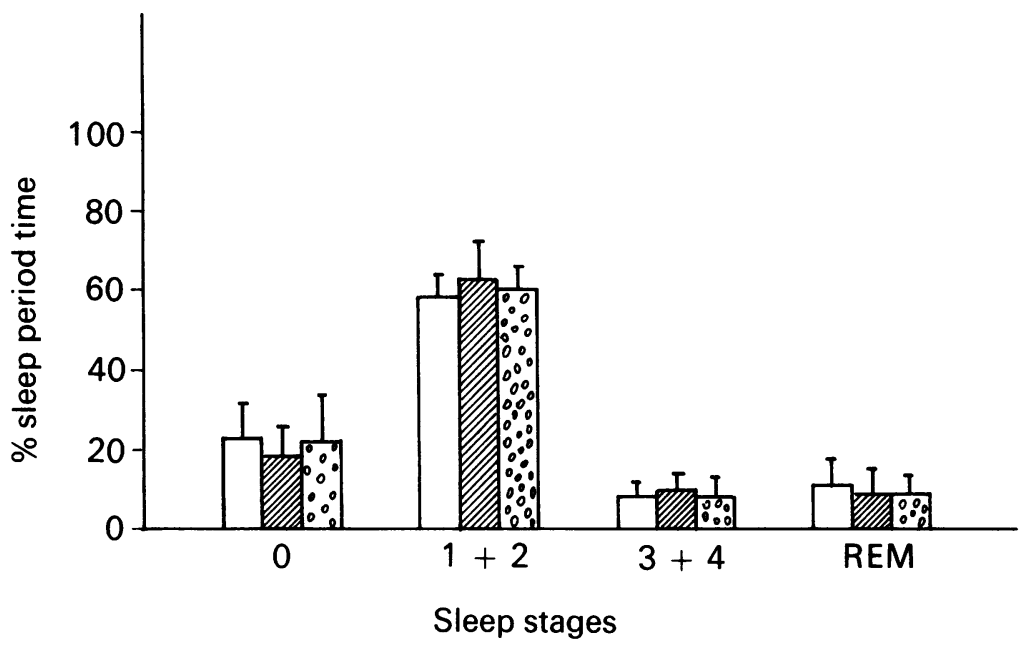

Mean (SD) duration of sleep stages expressed as percentages of sleep period time after

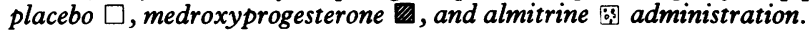

improvement in oxygen saturation than medroxyprogesterone (table 5).

We calculated the probable mean fall in $\mathrm{PaO}_{2}\left(\triangle \mathrm{PaO}_{2}\right)$ from $\mathrm{PaO}_{2}$ values when the patients were awake, using mean $\mathrm{SaO}_{2}$ during stage 2 and the oxyhaemoglobin dissociation curve and assuming that $\mathrm{pH}$ values, body temperature, and $P_{50}$ (half oxygenation tension of haemoglobin) were unchanged during stage 2 sleep (table 6). The calculated $\Delta \mathrm{PaO}_{2}$ was lower during almitrine treatment than with medroxyprogesterone or placebo, though the difference was not significant.

\section{Discussion}

Patients with chronic obstructive pulmonary disease and carbon dioxide retention usually have normal respiratory drive and normal minute ventilation. ${ }^{10}$ Carbon dioxide retention is caused by insufficient respiratory effort and an abnormal breathing pattern in the presence of serious disturbances of the distribution of lung perfusion. ${ }^{11}$ Respiratory stimulants with a beneficial effect on the pattern of breathing may

Table 4 Mean (SD) values for arterial oxygen saturation $(\%)$ during the different sleep stages in the six patients

\begin{tabular}{lllll}
\hline & Placebo & Medroxyprogesterone & Almitrine & Placebo-almitrine \\
\hline Awake & $85(2)^{\star}$ & $88(2)^{\star}$ & $89(2)$ & $<0.001$ \\
Stage 1 & $77(3)$ & $81(6)$ & $83(3)$ & $<0.01$ \\
Stage 2 & $76(3)$ & $79(5)$ & $82(4)$ & $<0.01$ \\
Stage 3 +4 & $73(8)$ & $76(8)$ & $79(5)$ & $<0.05$ \\
REM $(\mathrm{n}=5)$ & $61(9)$ & $66(9)$ & $68(11)$ & $<0.01$ \\
\hline
\end{tabular}

${ }^{\star} \mathrm{p}<0.01$ (paired $t$ test).

Table 5 Arterial oxygen saturation $\left(\mathrm{SaO}_{2}\right)$ during sleep after administration of placebo, medroxyprogesterone and almitrine

\begin{tabular}{lcll}
\hline & Placebo & Medroxyprogesterone & Almitrine \\
\hline Lowest $\mathrm{SaO}_{2}$ during sleep $(\%)$ & $41(19)$ & $45(23)$ & $55(13)$ \\
Duration $(\mathrm{min}) \mathrm{SaO}_{2}<80 \%$ & $122(35)^{\star \star}$ & $85(48)$ & $62(22)^{\star \star}$ \\
Total $\mathrm{No}$ of hypoxaemic episodes & $28(7)^{\star}+$ & $19(8)^{\star}$ & $16(5) \dagger$ \\
\hline
\end{tabular}

${ }^{\star} \mathrm{p}<0.05,{ }^{\star \star} \mathrm{p}<0.01,+\mathrm{p}<0.001$ (paired $t$ test). have a place in therapeutic management of these patients.

Non-apnoeic oxyhaemoglobin desaturation is known to occur in patients with chronic obstructive lung disease, mainly in association with REM sleep, and this may have deleterious consequences for the prognosis of these patients. Low $\mathrm{PaO}_{2}$ and high $\mathrm{PaCO}_{2}$ during wakefulness are predictors of deterioration of hypoxaemia during sleep. ${ }^{1}$ The principal causative mechanisms for nocturnal desaturation are alveolar hypoventilation and an increase in the degree of $\dot{V} / \dot{Q}$ disturbance. ${ }^{12} 13$

Although the exact mechanism of respiratory stimulation caused by medroxyprogesterone is still obscure, it is believed to operate directly on the respiratory centre after crossing the blood-brain barrier. ${ }^{14}$ Medroxyprogesterone increases respiratory drive, ${ }^{11}$ the ventilatory and neuromuscular response to hypercapnia, ${ }^{15}$ and the ventilatory response to hypoxia,${ }^{16}$ and it restores the impaired load compensation in patients with chronic obstructive lung disease. ${ }^{17}$ When the patients react favourably to medroxyprogesterone, an increase in their tidal volume and mean inspiratory flow is observed that persists during sleep. ${ }^{3}$ According to Skatrud, ${ }^{18}$ all our patients can be defined as "correctors" as they showed a greater than 5 $\mathrm{mm} \mathrm{Hg}(0.67 \mathrm{kPa})$ decrease in $\mathrm{PaCO}_{2}$. The remarkable increase in $\mathrm{A}-\mathrm{aDO}_{2}$ in our patients after medroxyprogesterone shows that the increase in ventilation is not accompanied by an appropriate increase in their $\mathrm{PaO}_{2}$. To interpret this we would need detailed information about pattern of breathing, cardiac output, and $\dot{\mathrm{V}} / \mathbf{Q}$ distribution.

On the other hand, almitrine stimulates peripheral chemoreceptors, ${ }^{19}$ increases the ventilatory response to hypoxaemia ${ }^{20}$ and alveolar ventilation, ${ }^{21}$ and has a beneficial effect on the ventilation-perfusion relationship. ${ }^{22}$ The changes in the pattern of breathing seen with almitrine consist of a faster, deeper, and shorter inspiration followed by a longer expiration without any change in breathing frequency. ${ }^{23}$ The significant improvement in arterial blood gas tensions without a significant change in $\mathrm{A}-\mathrm{aDO}_{2}$ after almitrine suggests some normalisation of $\dot{\mathrm{V}} / \dot{Q}$ matching in conjunction with the increase in ventilation (otherwise $\mathrm{A}-\mathrm{aDo}_{2}$ would be expected to have fallen). Almitrine has a positive effect on the distribution of ventilation ${ }^{21}$ in addition to redistributing blood flow to areas with better ventilation. ${ }^{24}$

Both medroxyprogesterone and almitrine have been shown to improve blood oxygenation during wakefulness and sleep. Our comparison of the two shows that almitrine in the doses we used increases $\mathrm{PaO}_{2}$ during wakefulness more than does medroxyprogesterone. Furthermore, almitrine significantly improved oxygenation during sleep by comparison with placebo, whereas the improvement after medroxyprogesterone administration was not significant. The calculated change in arterial oxygen pressure $\left(\Delta \mathrm{PaO}_{2}\right)$ after almitrine during stage 2 sleep suggests that the improvement in oxygenation with almitrine is not due only to the higher baseline $\mathrm{SaO}_{2}$ during wakefulness. 
Table 6 Mean (SD) arterial oxygen saturation $\left(\mathrm{SaO}_{2}\right)$ during wakefulness and stage 2 sleep, the corresponding arterial oxygen tension $\left(\mathrm{PaO}_{2}\right)$ calculated from the oxyhaemoglobin dissociation curve, and the fall in $\mathrm{PaO}_{2}\left(\Delta \mathrm{PaO}_{2}\right)$ between wakefulness and sleep after placebo, medroxyprogesterone, and almitrine administration in the six patients

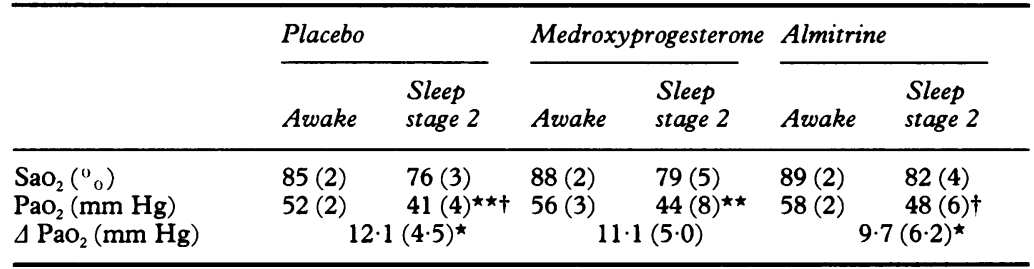

${ }^{\star} 0.1>\mathrm{p}>0.05,{ }^{\star \star} \mathrm{p}<0.05,+\mathrm{p}<0.01$ (paired $t$ test). $1 \mathrm{~mm} \mathrm{Hg} \approx 0.133 \mathrm{kPa}$.

This is in agreement with the finding of Catterall et al, ${ }^{25}$ who showed that the level of arterial oxygenation when the patient is awake is not the sole determinant of the degree of nocturnal hypoxaemia.

The basic sleep architecture was not affected significantly by either drug. It is remarkable that the number of arousals increased after medroxyprogesterone administration. Sleep disturbance in patients with chronic obstructive lung disease is multifactorial. ${ }^{26}$ Hypoxaemia and hypercapnia are two probable causes. ${ }^{27}$ The large rise in the number of arousals after medroxyprogesterone was possibly the result of the combined augmentation of the chemosensitivity to hypercapnia (mainly) and to hypoxia that was documented during wakefulness.

Although, according to Voelkel, 28 "the elusive mechanisms of alveolar hypoxia induced constriction of lung vessels are still one of the vexing problems of respiratory physiology," this mechanism has been claimed to originate, in part at least, from peripheral chemoreceptors ${ }^{29}$ and in part from the lung. ${ }^{30}$ Almitrine is known to stimulate peripheral chemoreceptors directly and experimental studies have shown that it causes pulmonary vasoconstriction, producing a local action on the lung. ${ }^{31}$ Almitrine probably enhances the rapid changes in perfusion distribution that follow the uneven changes in the distribution of ventilation during hypoventilation episodes, thus preventing further $\dot{V} / Q$ inequalities and securing a higher $\mathrm{PaO}_{2}$ during sleep.

We conclude that both almitrine and medroxyprogesterone can improve blood gases during wakefulness in patients with chronic obstructive lung disease and carbon dioxide retention. In the doses used, however, almitrine seemed somewhat more effective in improving nocturnal oxygen saturation.

1 Fletcher EC, Miller J, Divine GW, Fletcher JG, Miller T Nocturnal oxyhemoglobin desaturation in COPD patients with arterial oxygen tensions above $60 \mathrm{~mm} \mathrm{Hg}$. Chest 1987;92:604-8.

2 Connaughton JJ, Douglas NJ, Morgan AD, et al. Almitrine improves oxygenation when both awake and asleep in patients with hypoxia and carbon dioxide retention caused by chronic bronchitis and emphysema. Am Rev Respir Dis 1985;132:206-10

3 Skatrud JB, Dempsey JA, Iber C, Berssenbrugge A. Correction of $\mathrm{CO}_{2}$ retention during sleep in patients with chronic obstructive pulmonary disease. Am Rev Respir Dis $1981 ; 124: 260-8$

4 Voisin C, Howard P, Ansquer JC. Almitrine bismesylate: a long-term placebo-controlled double blind study in coadVectarion international multicentre study group. Bull Eur Physiopathol Respir 1987;23:169-82S.

5 Tweney J. Almitrine bismesylate: current studies. Bull Eur Physiopathol Respir 1987;23:153-63S

6 Cotes JE. Pulmonary function: principles and applications in medicine. Oxford: Blackwell, 1975.

7 Read DJC. A clinical method for assessing the ventilatory response to carbon dioxide. Aust Ann Med 1967;16:20-32.

8 Daskalopoulou E, Patakas D, Tsara V, Kazis A, Maniki E, Zoglopitis F. Almitrine effect on nocturnal hypoxaemia in patients with COPD. Bull Eur Physiopathol Respir 1987;23:185-90S

9 Rechtschaffen A, Kales A. A manual of standardized terminology, techniques and scoring system for sleep stages of human subjects. Los Angeles: Brain Information Service/Brain research Institute, University of California, 1968.

10 Sorli A, Grassino A, Lorange G, Milic-Emili J. Control of breathing in patients with chronic obstructive lung disease. Clin Sci Mol Med 1978;54:295-304.

11 Skatrud JB, Dempsey JA. Relative effectiveness of acetazolamide versus medroxyprogesterone acetate in correction of chronic carbon dioxide retention. $\mathrm{Am} \mathrm{Rev}$ Respir Dis 1983;127:405-12.

12 Stradling JR, Lane DJ. Nocturnal hypoxaemia in chronic obstructive pulmonary disease. Clin Sci 1983;64:213-22.

13 Catterall JR, Calverley PMA, Mac Nee W, et al. Mechanism of transient nocturnal hypoxaemia in chronic bronchitis and emphysema. J Appl Physiol 1985;59:1698-703.

14 Dolly FR, Block AJ. Medroxyprogesterone acetate and COPD. Effect on breathing and oxygenation in sleeping and awake patients. Chest 1983;84:394-8.

15 Skatrud JB, Dempsey JA, Kaiser DG. Ventilatory response to medroxyprogesterone acetate in normal subjects: time course and mechanism. J Appl Physiol 1978;44:939-44.

16 Zwillch CW, Natalino MR, Sutton FD, Weil JV. Effects of progesterone on chemosensitivity in normal men. $J$ Lab Clin Med 1978;92:262-9.

17 Kimura H, Tatsumi K, Kuriyama T, et al. Effect of chlormadione acetate, a synthetic progesterone, on restoring impaired load compensation in chronic obstructive pulmonary disease. Tohoku J Exp Med 1986;149:119-32.

18 Skatrud JB, Dempsey JA, Bhansali P, Irvin C. Determinant of chronic carbon dioxide retention and its correction in humans. J Clin Invest 1980;65:813-21.

19 Laubie M, Diot F. A pharmacological study of the respiratory stimulant action of S2620. J Pharmacol 1972 3:363-74.

20 Stradling JR, Barnes P, Pride NB. The effects of almitrine on the ventilatory response to hypoxia and hypercapnia in normal subjects. Clin Sci 1982;63:401-4.

21 Bee D. Changes in breathing pattern caused by almitrine in hypoxic/hypercapnic ferrets. J Physiol 1986;378:68P.

22 Powles ACP, Tuxen DV, Mahood B, Pugsley SO, Campbell EJM. The effect of intravenously administered Almitrine, a peripheral chemoreceptor agonist, on patients with chronic air-flow obstruction. Am Rev Respir Dis 1983;127:284-9.

23 Stradling JR, Nicholl LG, Lover D, Davies EE, Hughes JMB, Pride NB. The effects of oral almitrine on pattern of breathing and gas exchange in patients with chronic obstructive pulmonary disease. Clin Sci 1984;66:435-42.

24 Melot C, Naeije R, Rothchild T, Mertens P, Mols P, Hallemans $R$. Improvement in ventilation-perfusion matching by almitrine in COPD. Chest 1983;83:528-33.

25 Catterall JR, Douglas NJ, Calverley PMA, Shapiro CM Flenley DC. Arterial oxygenation during sleep in patients with right-to-left cardiac or intrapulmonary shunts. Thorax 1983;38:344-8.

26 Cormick W, Olson LG, Hensley MJ, Saunders NA. Nocturnal hypoxaemia and quality of sleep in patients with chronic obstructive lung disease. Thorax 1986;41:846-54.

27 Fleetham J, West P, Mezon B, Conway W, Roth T, Krygge $M$. Sleep, arousals and oxygen desaturation in chronic obstructive pulmonary disease. Am Rev Respir Dis 1982;126:429-33.

28 Voelkel NF. Mechanism of hypoxic pulmonary vasoconstriction. Am Rev Respir Dis 1986;133:1186-95.

29 Daly M de B. Peripheral arterial chemoreceptors and the cardiovascular system. In: Acker H, O'Regan RG, eds Physiology of the peripheral arterial chemoreceptors. Amsterdam: Elsevier, 1983:325-93.

30 Fishman AP. Vasomotor regulation of the pulmonary circulation. Annu Rev Physiol 1980;42:211-20.

31 Bee D, Gill GW, Emery CJ, Salmon GL, Evans TW, Barer GR. Action of almitrine on the pulmonary vasculature in ferrets and rats. Bull Eur Physiopathol Respir 1983; 19:539-45. 